\title{
Evolution of vestibular schwannoma surgery: the long journey to current success
}

\author{
Andrei Koerbel, M.D., Alireza Gharabaghi, M.D., Sam SafaVi-Abbasi, M.D., \\ Marcos Tatagiba, M.D., Ph.D., and MadjID Samit, M.D., Ph.D. \\ Department of Neurosurgery, International Neuroscience Institute, Hannover; and Department of \\ Neurosurgery, University Hospital of Tübingen, Germany
}

\begin{abstract}
The extraordinary improvement of patient outcome after surgical treatment for vestibular schwannomas is relatively recent and has occurred mainly over the last 30 years. The introduction of microsurgical techniques has resulted in increasing degrees of precise anatomical and functional preservation of the facial and cochlear nerves. An expanded microsurgical technique accompanied by continuous electrophysiological monitoring has resulted in marked changes in the primary goals for this surgery. Whereas in the past the primary goal of vestibular schwannoma management was to preserve the patient's life, the objective in vestibular schwannoma treatment today is to preserve neurological function.

Long-term follow-up examinations show negligible recurrence rates, indicating that the aim of preservation of nerve function does not limit the completeness of tumor removal with modern neurosurgical techniques. Despite these advances in preserving the anatomical integrity of, for example, the cochlear nerve, losses of function and even deafness may occur postoperatively in some cases. Current biological and technical research in experimental and clinical settings addresses these problems. In this article, the authors report in detail the developments achieved in vestibular schwannoma surgery and the great clinicians to whom these results can be credited.
\end{abstract}

\section{KEY WORDS • acoustic neuroma • vestibular schwannoma - microsurgery • cerebellopontine angle • history of neurosurgery}

The overall development of neurosurgery during the last century was accompanied by profound improvements in patient outcome after vestibular schwannoma surgery. Nevertheless, this history was also characterized by extreme and tragic difficulties, including high morbidity and mortality rates.

The achievements in vestibular schwannoma surgery were conspicuously marked by the following advances: 1 ) a better understanding of the microsurgical anatomy; 2) the current use of the operating microscope; and 3) the significant advances in neuroanesthesia, neurophysiology, and in standard operative techniques during the last 30 years. In this paper we provide an overview of the history of vestibular schwannoma treatment and the milestones that were achieved during this time. For the sake of consistency with historical works, we will often use the term "acoustic neuroma," although many now consider that term obsolete.

\section{First Descriptions of Vestibular Schwannomas}

As reported by Ahn, et al., ${ }^{1}$ in 1777 Eduard Sandifort, a professor of anatomy in the Netherlands, described at autopsy the first unilateral acoustic tumor. Wishart ${ }^{69}$ re- ported the first known case of bilateral acoustic neuromas in 1822: he described a patient who became progressively deaf in both ears, blind, had intractable vomiting and headaches, and facial twitching. The patient died at 21 years of age, and at autopsy Wishart found numerous tumors in the skull. Among these tumors, he described the following: "The seventh cranial nerve pair was diseased in the same manner; a tumor of the size of a small nut, and very hard, being attached to each of them, just where they enter the meatus auditorius internus." ${ }^{69}$ Sir Charles Bell ${ }^{10}$ (1774-1842) provided the first known report of a case of Meckel cave neuroma (a case diagnosed at autopsy) in 1833, demonstrating the relationship of the tumor to the cerebellopontine angle.

Jean Cruveilhier ${ }^{15}$ (1791-1874) was the first professor of pathological anatomy in Paris and he provided the first color illustrations of brain pathology in his atlas. ${ }^{54} \mathrm{He}$ described specimens of olfactory groove meningioma and a cerebellopontine angle tumor. As recounted by Pearce ${ }^{54}$ and Spillane, ${ }^{63}$ Cruveilhier attended a 26 -year-old woman in the last 3 months of her life. Cruveilhier related that the onset of disease was with headaches and that the patient 
lost her hearing at the age of 19 years. She became progressively blind, there were convulsive movements of the left side of her face, and "she got up every day" until the last month. At autopsy, Cruveilhier found a large tumor in the posterior fossa that was compressing the cerebellum and the brainstem, involvement of the fifth to 11th cranial nerves, and bilateral optic atrophy. The tumor was adherent to the back of the petrous bone and had eroded the internal auditory meatus.

\section{Surgery of Cerebellopontine Angle Processes}

The first reported case of successful surgery in the cerebellopontine angle (that is, in which the patient survived) was performed in 1894 by a British surgeon, Sir Charles Ballance (1856-1936). ${ }^{8}$ Ballance popularized the operation of radical mastoidectomy for advanced middle ear infection in 1890 and he also demonstrated cranial base approaches to treat infectious thrombophlebitis of the petrosal, lateral, and cavernous sinus. ${ }^{64}$

The patient treated by Ballance in 1894 was a 49-yearold woman who presented with headache, tinnitus, and vertigo that had lasted for 1 year. Six months before surgery she presented with right-sided hearing loss, vomiting, and progressive worsening of her overall condition. Ataxia and papilledema were additionally described. She underwent a posterior fossa craniectomy. Ballance described his findings as follows: "Solid tumor found attached to the dura over inner part of posterior surface of petrous. Somewhat firmly fixed, and the finger had to be insinuated between pons and tumor to get it away." During the postoperative follow-up period the fifth and seventh cranial nerves were injured, and the right ulcerated eye had to be removed. The patient was still alive in 1907 but had persistent cranial nerve deficits. The pathological entity was reported as a fibrosarcoma; however, the neuromas were frequently described as gliosarcomas or fibrosarcomas at that time. ${ }^{64}$ Some authors propose that Ballance actually could have removed a meningioma of the cerebellopontine angle, and not a neuroma. ${ }^{3}$

In 1894, Ballance unsuccessfully attempted direct union of the facial nerve within the temporal bone. ${ }^{64}$ In 1895, he was the first surgeon in the antiseptic era to perform a spinal accessory nerve-facial nerve anastomosis to treat facial palsy. $6,7,964,68$ There were some problems related to such a technique, such as the occurrence of sternocleidomastoid and trapezius muscle paresis and atrophy, and the patients were unable to perform independent facial movements without associated movements of these two muscles as well. ${ }^{6}$ Then, Ballance performed a hypoglossal nerve-facial nerve anastomosis in 1903 (an operation that had been performed for the first time by W. Korte of Germany in 1901), ${ }^{64}$ with a more favorable outcome than the anastomosis with the accessory nerve. ${ }^{7,9}$ In 1913, Ballance further tried to develop the hypoglossal-facial nerve anastomosis technique, performing the procedure by joining the descending branch of the hypoglossal nerve to the distal hypoglossal nerve to minimize atrophy of the tongue. ${ }^{64}$

At the National Hospital in London, in 1905, Horsley achieved total removal of an acoustic neuroma and the patient survived, but became severely disabled due to brainstem ischemia, which resulted from a lesion of the anterior inferior cerebellar artery. ${ }^{67}$ In the same year, Borchardt performed the first transsigmoidal approach for resection of an acoustic neuroma, and in 1906 he reported his surgical results for cerebellopontine angle tumors, describing 18 cases that included 13 deaths. ${ }^{13}$

An atlas of neurosurgery published by Fedor Krause (1857-1937) contains a detailed description of techniques used in the treatment of posterior fossa disease..$^{38}$ In 1898 , he created a suboccipital osteoplastic craniotomy and cut the eighth cranial nerve to treat Ménière syndrome. Krause $^{39}$ reported that acoustic neuromas could be removed by surgery, and in his monograph (1909-1912) he described and illustrated his technique of removing tumors in the cerebellopontine angle by using a finger. Describing his results in cerebellopontine angle tumor resection, Krause reported 31 cases with 26 deaths. ${ }^{37}$ At the International Congress of Medicine in London, Horsley, Eiselberg, and Krause reported mortality rates ranging from 67 to $84 \%$. 18,57

As related by Ahn, et al., in 1903 an attempt was made by Garré to remove bilateral acoustic tumors that were found intraoperatively. Nevertheless, the patient died and the postmortem examination showed widespread neurofibromatosis.

Biggs described a case of bilateral acoustic neuromas and other intracranial tumors, as well as the results:

On November 19th Mr. McGavin reopened the wound ... the hemorrhage was only stopped after the application of forceps. The cerebellum bulged extensively into the wound, but no tumor could be felt or seen. The patient lost a considerable amount of blood and saline had to be administered per rectum. The wound was sutured and dressed, the forceps being left in situ, and the patient was sent back to the bed. On the 22nd Mr. McGavin, under chloroform, removed the forceps and plugging, but the hemorrhage was so severe that they had to be replaced.... The patient died at 2:30 AM on the 24th. ${ }^{11}$

As related in Goodrich, ${ }^{28}$ Thierry de Martel (18751940), a pioneer of French neurosurgery, had a special interest in tumors of the cerebellopontine angle. De Martel, who trained initially as an engineer, introduced the sitting position for posterior fossa surgery; previously there were descriptions of only the lateral or prone positions. With Joseph Babinski, who is known for describing the cutaneous plantar reflex, de Martel reported the case of a patient with a surgically treated acoustic neuroma who showed rapid clinical improvement. ${ }^{5,41}$

In 1916, Henschen ${ }^{30}$ submitted a large clinical series, with 245 verified cases of unilateral and 24 bilateral acoustic neuromas, 19 of which were associated with neurofibromatosis. He discovered, by evaluating autopsy samples, that acoustic neuromas originate in the vestibular portion of the nerve lying in the porus acusticus. ${ }^{1}$

Harvey Cushing (1869-1939), the father of American neurosurgery, together with Amory Codman, both trying to anticipate the changes in vital signs that led to death, 12 were the first to record the patient's intraoperative pulse, temperature, respiration, and ether dosage during anesthesia. ${ }^{35}$ These innovations paved the way to enormous advances in the development of neuroanesthesia. Cushing developed the use of silver clips for hemostasis within the brain and later introduced the use of electrocautery in cerebral tumor operations. ${ }^{22}$ In 1904, he presented his first reports on the surgeries in which monitoring of vital signs was used, but there were no survivors after craniotomy for tumors. ${ }^{45}$ 
Cushing ${ }^{16}$ described 30 cases of acoustic neuromas and published the famous Tumors of the Nervus Acusticus and the Syndrome of the Cerebellopontine Angle in 1917. He posited that an intracapsular removal would be safer than attempting to separate the tumor from the brainstem and the cranial nerves. In patients treated using this technique, Cushing claimed much better results than those previously reported, reducing fatalities to a range of 10 to $15 \%$. Nevertheless, the mortality rate from recurrence was 54\% at 5 years. ${ }^{16,57}$

Ballance $^{6}$ published in 1919 his classic, Essays on the Surgery of the Temporal Bone, which contains figures with precise anatomical details. ${ }^{64}$ Ballance and Duel published in 1932 the monograph The Operative Treatment of Facial Palsy, describing several techniques. The best results without associated movements were achieved with intratemporal, sutureless nerve grafting. ${ }^{64}$

Cushing's pupil, Walter E. Dandy (1886-1946), did not accept the high rates of recurrence from acoustic neuromas reported by Cushing. Dandy ${ }^{18}$ showed that acoustic neuromas could be resected in their totality, and might be associated with a lower mortality rate if, rather than a simple intracapsular removal, a capsular dissection was performed with meticulous techniques. In 1922, Dandy ${ }^{17}$ published this strategy and technique and did not mention the earlier Cushing paper. As a result, Cushing sent a letter to the director of the hospital questioning Dandy's conduct. ${ }^{28}$

In 1925, Dandy ${ }^{18}$ described complete tumor removal in five patients in whom a bilateral suboccipital craniectomy was used, and later modified this to a unilateral craniectomy. In 1941 he reported a mortality rate of $10.87 \%$ after complete removal of 46 acoustic neuromas via a unilateral approach. ${ }^{19}$ Nevertheless, he managed to preserve the facial nerve in only one of 45 surgically treated cases.

In 1921, Vilhelm Magnus (1871-1929) published his results in 31 patients who underwent operations for trigeminal neuralgia by a resection of the pontine nerve root or gasserian ganglion, with pain relief achieved in all but one. ${ }^{46,47}$ At the annual meeting of the Scandinavian Surgical Association in Copenhagen in 1925, he presented his results from the brain tumor surgery with the following remarks:

Brain surgery ... the mortality being horrific. Fedor Krause, for example, has a mortality of $50 \%$, Küttner $45 \%$ and von Eiselsberg $40 \%$. For operations such as extirpation of acoustic nerve tumors the mortality is over $80 \%$... in my opinion, this view is baseless defeatism, for Cushing has a mortality of $8,4 \%$ and I myself of $10,5 \%$. The reason for Cushing and myself having so much lower a mortality than the surgeons named above is quite simple: the general surgeon does not have sufficient training, either theoretical or technical, for this demanding branch of surgery. ${ }^{48}$

According to Fodstad, et al., ${ }^{25}$ in 1926 Magnus declared that his surgical mortality rate in 161 patients with supratentorial tumors was $8 \%$, whereas it was $17 \%$ in 55 patients with infratentorial tumors. There was only one death among 14 patients with acoustic neuromas.

After a 5-week visit to Cushing in 1928, Magnus reported the following about his host:

... He said that he considered operations for tumors of the acoustic nerve to be the most exacting ones he knew, and he had harsh judgment to pronounce on those surgeons who without the requisite experience undertook these operations, which in the hands of an inexperienced surgeon were desperate remedies indeed. ...49

As Shambaugh ${ }^{62}$ relates, in 1935 Norman Dott of Edinburgh successfully inserted a long graft from the stump of the facial nerve near the brainstem at the stylomastoid foramen, following removal of an acoustic neuroma. In 1949, Horrax and Poppen ${ }^{31}$ supported Dandy's philosophy, and reported the advantage of complete removal of acoustic neuromas. They cited a 5-year mortality rate of $12.7 \%$, which was much lower than the 54 to $56 \%$ mortality rate associated with intracapsular decompression.

Herbert Olivecrona (1891-1980) graduated as a physician in Stockholm. At the age of 31 years, he performed surgery on his first brain tumor, in a patient who had a brain metastasis. ${ }^{43}$ The tumor was not localized in the surgery and the patient died of massive swelling with herniation of brain tissue. His second patient, who had an acoustic neuroma, could not be adequately positioned, because the face was pointing down as required for the operation. Olivecrona mounted the head cap from a hairdryer of the kind (rafraicheur) used in beauty salons at that time, so that the patient's head could be supported face down. ${ }^{43,44}$ This surgical intervention took 6 hours and the patient survived only 18 days. Seventeen years later, in 1939, Olivecrona demonstrated that the facial nerve could be preserved in the surgical treatment of acoustic neuromas, with a rate of preservation of $65 \%$, extraordinary results for that time..$^{28,52,57} \mathrm{He}$ further described a series with 300 patients and 148 complete tumor removals. Facial function was preserved in 69 of these patients. ${ }^{27}$ The mortality rate was similar in the groups with partial and total removal ( 29\%). Late follow-up reviews of Olivecrona's patients showed, however, that half of them either had a recurrence or died of one. ${ }^{31,58}$

Until 1964, the suboccipital approach was used in the vast majority of surgeries for acoustic neuromas. ${ }^{57}$ In the 1960 s, the use of steroid drugs was introduced to reduce cerebral edema. ${ }^{4}$

\section{Development of Microsurgery and the Modern Management of Vestibular Schwannomas}

In 1904, Panse ${ }^{53}$ demonstrated the translabyrinthine approach, which was then not used for the next 60 years..$^{57}$ In the 1960s, House developed the middle fossa approach and applied it to acoustic neuromas and other diseases of the internal auditory canal. ${ }^{32,33} \mathrm{He}$ realized, however, the limited exposure provided by this approach and further developed new options for approaching tumors of the cerebellopontine angle. House had observed the use of an operating microscope in otorhinolaryngology surgeries performed by Wülstein in Germany (L Osterwald, personal communication). House applied the microscope and microsurgical techniques to the translabyrinthine approach, becoming adept at preserving the facial nerve at excellent rates for that era and reducing the operative mortality rate..$^{20,57}$

The otolaryngologists were the first to use the operating microscope in clinical surgery, followed by ophthalmologists, vascular surgeons, and plastic surgeons, who started to use the microscope in the operating room after World War II. ${ }^{40}$ In 1957, at the University of Southern California, Theodore Kurze used an operating microscope for the first 
time in neurosurgery. In this landmark operation, Kurze removed a neurilemmoma of the seventh cranial nerve in a 5-year-old patient. In 1960, he established the world's first cranial base microsurgical laboratory.

In 1965, Rand and Kurze ${ }^{55,56}$ reported suboccipital transmeatal microdissection to remove acoustic tumors totally, affording the possibility of preservation of the facial, vestibular, and cochlear nerves. The suboccipital approach could potentially preserve the auditory function, which would not be possible via the translabyrinthine approach.

Leksell ${ }^{42}$ described stereotactic radiosurgery in 1951 as a method to destroy intracranial targets by using single high doses of focused ionizing radiation, controlled by stereotactic guidance. As Niranjan and Lunsford ${ }^{51}$ recount, in Stockholm in 1967, Leksell and E. O. Backlund performed the first gamma knife procedure, and 2 years later, in 1969, Leksell and G. Norén performed the first radiosurgery to treat an acoustic neuroma. Recent series reporting long-term outcomes in patients with acoustic neuromas who were treated radiosurgically show a high rate of facial and cochlear nerve preservation, along with long-term tumor control..$^{26,36}$

Mahmut Gazi Yaşargil, a young Turkish neurosurgeon, returned to Zürich after completing a year of microsurgical training in Vermont and successfully performed the first superficial temporal artery-middle cerebral artery bypass in 1967. ${ }^{21}$ Yaşargil was influenced by the ideas of Kurze and others to make microsurgery a fundamental part of modern neurosurgery, thus dramatically transforming how neurosurgical procedures were done. , $24,40^{\mathrm{He}}$ created innovative instrumentation, such as the floating microscope, the self-retaining adjustable retractor, and microsurgical instruments. ${ }^{66}$

The development of computerized tomography, magnetic resonance imaging, and other imaging modalities, along with the introduction of neuromonitoring, all of which were associated with the aforementioned achievements in neurosurgery, allowed significant reductions in the morbidity accompanying cerebellopontine angle surgery. Several authors have recently reported increasing rates of facial and hearing preservation, associated with minimal mortality rates. . $^{14,23,29,60,61}$

In 1999, Yaşargil, in his article containing professional memories, wrote:

... Professor Samii had already trained in microsurgical dissection and repair of injured peripheral nerves with Professor Millesi in Vienna, Austria. He immediately recognized the capabilities of microtechniques and could envision their potential in neurosurgery. Initially, he entered the field of the cerebellopontine schwannoma, and in the following 30 years, he succeeded in mastering a world record achievement in schwannoma surgery. I had my first opportunity to visit Hannover and observe his professional activities in the summer of 1997, when he operated on two vestibular schwannomas. I recognized the importance of laboratory training for the dissection and repair of peripheral nerves. I had discovered a double arachnoid membrane enveloping schwannomas in the CPA [cerebellopontine angle] and developed techniques confining dissection between these layers to preserve brainstem, arteries, and basal nerves, particularly the facial, cochlear, and vestibular group. In general, there were good postoperative outcomes in 450 patients, and the results have been published in Microneurosurgery, volume IVB. In spite of this success, I have always been under great tension and in a state of high anxiety during the entire surgical procedure of a schwannoma, owing to my great respect for dissection of the cranial nerves. It was a joy, therefore, to witness that Madjid Samii remained totally relaxed and placid because he knew how to guide his manipulations with the nerve to promote dissection.... ${ }^{70}$

At that time, analysis of large series of patients showed rates of anatomical facial preservation of approximately $93 \%$, rates of hearing preservation of 39 to $47 \%$, and minimal mortality rates $(1 \%)$ in vestibular schwannoma resection. ${ }^{59-61}$

More recently, improved rates of hearing preservation have been achieved. Fifty-four percent of patients may attain preservation of their auditory function, with excellent results in small tumors (up to $71 \%$ of cases) and with relevant numbers and at satisfactory quality levels even in large tumors. ${ }^{50}$

In a recent analysis (in 2004) of Professor Samii's last 200 vestibular schwannoma operations, facial nerve preservation was possible in $100 \%$ of the cases in Class T1 to T3 tumors (small lesions) and 97\% in Class T4 tumors (large lesions). The rates of hearing preservation were still improving and there were no deaths (unpublished data).

Although there have been major improvements in the prevention of deafness by function-conserving microsurgery, there is no alternative treatment option when the auditory nerve has lost its function, either because of surgery or tumor growth. Bilateral vestibular schwannomas typically occur in patients suffering from neurofibromatosis Type 2. When bilateral deafness occurs in these patients, standard hearing aids and prostheses (like cochlear implants) are not effective. Since 1979, House and Hitselberger $^{34}$ have shown that patients with bilateral deafness due to neurofibromatosis Type 2 can benefit from auditory sensation provided by auditory brainstem implants. These devices bypass both the cochlea and the eighth cranial nerve and directly stimulate neurons of the central auditory pathway. Since this pioneering work, almost 300 profoundly deaf patients have received an auditory brainstem implant for partial restoration of hearing function.

More recently, experimental studies ${ }^{65}$ have been performed to investigate biological regeneration of injured auditory nerves. In general, injury to the human and mammalian auditory nerve is associated with a lack of longdistance elongation and leads to definitive loss of the hearing function. To overcome this typical lack of functional regeneration in the central nervous system, a combined neurotrophic and antiinhibitory treatment is applied in experimental animal models. Intrathecal treatment with antibodies directed against myelin-associated neurite growth inhibitory proteins promotes significant elongation of the injured fibers of cochlear nerves. These regenerating fibers seem to navigate to the correct targets, and are able to establish synaptic connections for functional recovery. These findings may lead to future clinical applications for the regeneration of cochlear nerves.

Although the treatment protocol for vestibular schwannomas has improved significantly over the years, further improvements for the management of these lesions can and will certainly be achieved in the near future. The current and future achievements were made possible by the contributions of the noteworthy and industrious clinicians presented in this article. 


\section{References}

1. Ahn MS, Jackler RK, Lustig LR: The early history of the neurofibromatoses. Evolution of the concept of neurofibromatosis type 2. Arch Otolaryngol Head Neck Surg 122:1240-1249, 1996

2. Al-Mefty O: M. Gazi Yaşargil: the time in Little Rock. Neurosurgery 45:1019-1024, 1999

3. al-Rodhan NR, Laws ER Jr: Meningioma: a historical study of the tumor and its surgical management. Neurosurgery 26: 832-847, 1990

4. Ausman JI: Achievements of the last century in neurosurgery and a view to the 21st century. Surg Neurol 53:301-302, 2000

5. Babinski J, de Martel T: Tumeur de l'angle pontocérebelleux: Amélioration rapide à la suite d'une extirpation intra-capsulaire par morcellements, in Babinski J (ed): Euvre Scientifique. Paris: Masson et Cie, 1934

6. Ballance CA: Essays on the Surgery of the Temporal Bone. London: Macmillan, 1919

7. Ballance CA: The operative treatment of chronic facial palsy of peripheral origin. Br Med J 1:1288, 1903

8. Ballance CA: Some Points in the Surgery of the Brain and Its Membranes, ed 2. London: Macmillan, 1908

9. Ballance CA, Ballance HA, Purves-Stewart J: Remarks on the operative treatment of chronic facial palsy of peripheral origin. Br Med J 1:1009-1013, 1903

10. Bell C: The Nervous System of the Human Body; Embracing the Papers Delivered to the Royal Society on the Subject of the Nerves. Washington, DC: Duff Green, 1833

11. Biggs GN: A case of multiple intracranial tumours with involvement of both auditory nerves. Lancet 2:14-15, 1909

12. Black PM: Harvey Cushing at the Peter Bent Brigham Hospital. Neurosurgery 45:990-1001, 1999

13. Borchardt M: Zur Technik der Blutstillung aus den Hirnblutleitern. Zentralbl Chir 40:1003, 1913

14. Comey CH, Jannetta PJ, Sheptak PE, et al: Staged removal of acoustic tumors: techniques and lessons learned from a series of 83 patients. Neurosurgery 37:915-921, 1995

15. Cruveilhier J: Anatomie pathologique du corps humain, ou Descriptions, avec figures lithographiées et coloriées, des diverses altérations morbides dont le corps humain est susceptible. Paris: Bailière, 1829-1842, Vol 2; Liv 32, Pl 2, pp 19-24; Liv 38, Pl 5, pp 1-4

16. Cushing H: Tumors of the Nervus Acusticus and the Syndrome of the Cerebellopontine Angle. Philadelphia: Saunders, 1917

17. Dandy WE: An operation for the total extirpation of tumors in the cerebello-pontine angle. A preliminary report. Bull Johns Hopkins Hosp 33:344-345, 1922

18. Dandy WE: An operation for the total removal of cerebellopontine (acoustic) tumors. Surg Gynecol Obstet 41:129-148, 1925

19. Dandy WE: Results of removal of acoustic tumors by the unilateral approach. Arch Surg 42:1026-1033, 1941

20. DiTullio MV Jr, Malkasian D, Rand RW: A critical comparison of neurosurgical and otolaryngological approaches to acoustic neuromas. J Neurosurg 48:1-12, 1978

21. Donaghy RM: Neurosurgeon of the year: Mahmut Gazi Yaşargil. Surg Neurol 13:1-3, 1980

22. Ellis H: Harvey Cushing and electrosurgery. Contemp Surg 19:73-75, 1981

23. Fahlbusch R, Neu M, Strauss C: Preservation of hearing in large acoustic neurinomas following removal via suboccipito-lateral approach. Acta Neurochir 140:771-778, 1998

24. Flamm ES: Professor M. Gazi Yaşargil: an appreciation by a former apprentice. Neurosurgery 45:1015-1018, 1999

25. Fodstad H, Ljunggren B, Kristiansen K: Vilhem Magnus-pioneer neurosurgeon. J Neurosurg 73:317-330, 1990

26. Foote KD, Friedman WA, Buatti JM, et al: Analysis of risk factors associated with radiosurgery for vestibular schwannoma. J Neurosurg 95:440-449, 2001
27. Givré A, Olivecrona H: Surgical experiences with acoustic tumors. J Neurosurg 6:396-407, 1949

28. Goodrich JT: A millennium review of skull base surgery. Childs Nerv Syst 16:669-685, 2000

29. Grabel JC, Zappulla RA, Ryder J, et al: Brain-stem auditory evoked responses in 56 patients with acoustic neurinoma. J Neurosurg 74:749-753, 1991

30. Henschen F: Zur Histologie und Pathogenese der Kleinhirnbrüchenwinkeltumoren. Arch Psychiatr 56:21-122, 1916

31. Horrax G, Poppen JL: The end results of complete versus intracapsular removal of acoustic tumors. Ann Surg 130:567-575, 1949

32. House WF: Middle cranial fossa approach to the petrous pyramid. Report of 50 cases. Arch Otolaryngol 78:460-469, 1963

33. House WF: Monograph I. Transtemporal bone microsurgical removal of acoustic neuromas. Arch Otolaryngol 80:597-756, 1964

34. House WF, Hitselberger WE: Twenty-year report of the first auditory brain stem nucleus implant. Ann Otol Rhinol Laryngol 110:103-104, 2001

35. Kiss I: From anaesthesia for neurosurgery to neuroanaesthesia: a historical note. Acta Neurochir 142:1391-1395, 2000

36. Kondziolka D, Lunsford LD, McLaughlin MR, et al: Long-term outcomes after radiosurgery for acoustic neuromas. N Engl J Med 339:1426-1433, 1998

37. Krause F: Discussion of von Eiselberg's paper. Trans Intl Con Med London VII:214, 1913 (Reference unverified)

38. Krause F: Ganglion Gasseri und der central davon gelegene Trigeminusstammes. Dtsch Med Wschr 19:341-344, 1893

39. Krause F: Surgery of the Brain and Spinal Cord, Based on Personal Experiences. New York: Rebman, 1909-1912

40. Kriss TC, Kriss VM: History of the operating microscope: from magnifying glass to microneurosurgery. Neurosurgery 42: 899-908, 1998

41. Lanzino G, diPierro CG, Laws ER Jr: One century after the description of the "sign": Joseph Babinski and his contribution to neurosurgery. Neurosurgery 40:822-828, 1997

42. Leksell L: The stereotaxic method and radiosurgery of the brain. Acta Chir Scand 102:316-319, 1951

43. Ljunggren B: Herbert Olivecrona: founder of Swedish neurosurgery. J Neurosurg 78:142-149, 1993

44. Ljunggren B, Sundbärg G: Svensk neurokirurgis historia. Hygiea 92:136-140, 1983

45. Long DM: Harvey Cushing at John Hopkins. Neurosurgery 45:983-989, 1999

46. Magnus V: Behandling av trigeminusneuralgi med alkoholinjektioner og exstirpation av trigeminusroten. Norsk Mag $\mathbf{f}$ Laegevidensk 82:420-424, 1921

47. Magnus V: Bidrag til hjernechirurgiens klinik og resultater. Norsk Mag f Laegevidensk (Suppl Merkur Bok \& Akcidenstrykkeri) 82:1-138, 1921

48. Magnus V: Erfaringer fra 20-aars hjernekirurgi. Proceedings of the 15th Annual Meeting of the Scandinavian Surgical Society in Copenhagen, 1925. Kristiania: Congress Proceedings, 1925, pp 193-197

49. Magnus V: Inntryk av Amerikansk Neurokirurgi. 5 Ukers Studieophold ved Peter Bent Brigham Hospital i Boston. 1928, p 9

50. Matthies C, Samii M: Vestibular schwannomas and auditory function: options in large T3 and T4 tumors? Neurochirurgie 48:461-470, 2002

51. Niranjan A, Lunsford LD: Radiosurgery: where we were, are, and may be in the third millennium. Neurosurgery 46:531-543, 2000

52. Olivecrona H: Acoustic tumors, in Winther K, Krabbe K (eds): III Congrès Neurologique International, Copenhague, 21/8-25/8 1939. Comptes Rendus des Séances. Copenhangue: Einar Munksgaard, 1939, pp 761-771

53. Panse R: Ein gliom des Akustikus. Arch Ohrenheilk 61: 251-255, 1904 
54. Pearce JM: Cruveilhier and acoustic neuroma. J Neurol Neurosurg Psychiatry 74:1015, 2003

55. Rand RW, Kurze T: Preservation of vestibular, cochlear, and facial nerves during microsurgical removal of acoustic tumors. Report of two cases. J Neurosurg 28:158-161, 1968

56. Rand RW, Kurze TL: Facial nerve preservation by posterior fossa transmeatal microdissection in total removal of acoustic tumors. J Neurol Neurosurg Psychiatry 28:311-316, 1965

57. Reidel C, Post KD: Complications in the treatment of acoustic neuromas, in Post KD, Friedman ED, McCormick P (eds): Postoperative Complications in Intracranial Neurosurgery. New York: Thieme, 1993, pp 91-110

58. Samii M, Draf W: Surgery of the Skull Base: An Interdisciplinary Approach. Berlin: Springer, 1989, pp 377-395

59. Samii M, Matthies C: Management of 1000 vestibular schwannomas (acoustic neuromas): hearing function in 1000 tumor resections. Neurosurgery 40:248-262, 1997

60. Samii M, Matthies C: Management of 1000 vestibular schwannomas (acoustic neuromas): surgical management and results with an emphasis on complications and how to avoid them. Neurosurgery 40:11-23, 1997

61. Samii M, Matthies C: Management of 1000 vestibular schwannomas (acoustic neuromas): the facial nerve-preservation and restitution of function. Neurosurgery 40:684-695, 1997

62. Shambaugh GE: History of facial nerve surgery, in Fisch U (ed): Facial Nerve Surgery. Amstelveen, The Netherlands: Kluger Medical Publications, 1977, pp 1-3

63. Spillane JD: The Doctrine of the Nerves: Chapters in the
History of Neurology. London: Oxford University Press, 1981, pp 205-211

64. Stone JL: Sir Charles Ballance: pioneer British neurological surgeon. Neurosurgery 44:610-632, 1999

65. Tatagiba M, Rosahl S, Gharabaghi A, et al: Regeneration of auditory nerve following complete sectioning and intrathecal application of the IN-1 antibody. Acta Neurochir 144: 181-187, 2002

66. Tew JM Jr: M. Gazi Yaşargil: neurosurgery's man of the century. Neurosurgery 45:1010-1014, 1999

67. Tooth HH: The treatment of tumors of the brain and the indications for operation. Trans 17th Intl Con Med Lond 7: 203-299, 1913 (Reference unverified)

68. Van de Graaf RC, Nicolai JP: Was Thomasz Drobnik really the first to operate on the facial nerve? Otol Neurotol 24:686-690, 2003

69. Wishart JH: Case of tumours in the skull, dura mater, and brain. Edin Med Surg J 18:393, 1822

70. Yaşargil MG: A legacy of microneurosurgery: memoirs, lessons, and axioms. Neurosurgery 45:1025-1092, 1999

Manuscript received February 24, 2005

Accepted in final form March 18, 2005.

Address reprint requests to: Andrei Koerbel, M.D., Department of Neurosurgery, Hoppe-Seyler-Strasse 3, 72076, Tübingen, Germany. email: andrei.koerbel@med.uni-tuebingen.de. 